\title{
Comparison of coagulation behaviour and floc characteristics of polyaluminium chloride (PAX 18, PAX XL19H, ALCAT) with surface water treatment
}

\author{
Izabela M. Bigaj, Renata Brzozowska, Michał Łopata, Grzegorz Wiśniewski, \\ Julita A. Dunalska, Daniel Szymański, Rafał A. Zieliński \\ Department of Environmental Protection Engineering, University of Warmia and Mazury, \\ Prawocheńskiego 1, 10-950 Olsztyn, Poland, e-mail: izabela.piorkowska@uwm.edu.pl (corresponding author)
}

\begin{abstract}
Coagulation behaviour of polyaluminium chloride (PACl) was comparatively investigated in terms of the removal of turbidity and colour with surface water. The growth of flocs was also compared. The results show that the decrease in saturation and values of dissolved oxygen was ca. 20\% for ALCAT and PAX 18 at both dosages and 15\% for PAX XL 19H, respectively. The floc formation growth indicated that PACl coagulation occurred not only by charge neutralization but also by a form of sweep flocculation. Besides, flocs formed by ALCAT had better sizes than the flocs formed by PAX 18 and PAX XL19H. The rate of sedimentation was stable during coagulation with higher doses, and it was dependent on the substance used.
\end{abstract}

Key words: polyelectrolyte, polyaluminium chloride, floc growth, sedimentation

\section{Introduction}

Removal of organic matter in surface water treatment is an essential requirement due to its rapid eutrophication. One of the compounds of organic matter is phosphorus. The major sources of phosphorus in water are domestic and industrial sewage, agriculture runoff, etc. Therefore effluents from human activities must be treated to remove the surplus $\mathrm{P}$, in order to maintain the ecological balance of natural systems (Conley et al. 2009). However, the internal loading is a significant source of nutrients to phytoplankton dynamics in water bodies (Harris 1997).

A common practice for the treatment of lakes is to use aluminium salt (Cooke et al. 1993; Rydin and Welch 1998; Haghseresht et al. 2009; Özkundakci et al. 2010). The immobilization of phosphorus in sediments may be described as the $\mathrm{Al}$ - floc accumulates on the sediment surface, with precipitate, inactivating sediment $\mathrm{P}$. The restoration of lakes by using aluminium salts depends on many factors, e.g. $\mathrm{pH}$, temperature, presence of oxygen, distribution of the floc, etc. (Rydin and Welch 1998; Zhao et al. 2011). Given the recognized role of sediment nutrient supply in summer phytoplankton activity, a variety of research projects are searching for a solution to lock P permanently to sediment. The most popular solution is to enhance sediment capacity by aluminium salts and their modifications. There is a great interest in the new coagulant with polyelectrolytes. Polyelectrolytes support the dynamics of floc formation and accelerate the sedimentation rate. Moreover, these compounds allow a large surface sorption of floc to be achieved.

Size and structure of flocs after flocculation cause a critical effect on the solid/liquid separation process (Yu et al. 2009). The floc growth is the balance between floc formation and breakage (Parker et al. 1972; Francois 1987; Spicer et al. 1996; Ducoste and Clark 1998; Biggs and Lant 2000). It is reported that small particles generally had lower removal efficiency by flocculation, since smaller particles generally settled down more slowly than larger particles of similar density. Li et al. (2007) also found that broken flocs were difficult to regrow. Reduced floc size slows down 
the sedimentation rate and changes particle transport mechanisms (Aguilar et al. 2003; Cleasby and Logsdon 1999). Chaignon et al. (2002) reported that the flocs formed by charge neutrality had complete recoverability. Therefore, floc strength and recoverability are considered as important parameters to provide valuable information in understanding the performance of a novel coagulant.

This work was performed to gain insights into the phosphate uptake by ALCAT, PAX XL19H and PAX 18 by studying its physicochemical properties. The purpose of this research was the comparison of coagulation behaviour and floc characteristics of polyaluminium chloride with surface water treatment.

\section{Methods}

Study locations. The tajskie Lake is a hypereutrophic lake, which drains a semi-rural and forest catchment. It is a shallow reservoir with a mean depth of $6.4 \mathrm{~m}$. Thermal stratification leads to hypoxic and anoxic conditions. Water quality in the lake is extremely poor with high nutrient concentrations in summer and autumn and cyanobacterial blooms through the summer. Mean TP concentrations have ranged from ca. $470 \mu \mathrm{g} \mathrm{dm}^{-3}$ (surface water) to $1078 \mu \mathrm{g} \mathrm{dm}^{-3}$ (bottom water).

Characteristics of coagulants. The experiment used the following coagulants: ALCAT, PAX 18 and PAX XL 19H. The ALCAT is a coagulant modified by polyelectrolyte (10\%), its $\mathrm{pH}$ is 1.0 and alkalinity ca. $40 \%$; the second (PAX 18) is a coagulant with very low $\mathrm{pH}$ (1.0) and alkalinity (21\%); the last (PAX XL 19H) is a coagulant with higher $\mathrm{pH}$ (3.5) and higher alkalinity $(85 \%)$. The density of all coagulants was similar $\left(1360 \mathrm{~kg} \mathrm{~m}^{-3}\right)$.

Experimental study. The experiment of phosphorus inactivation was carried out simultaneously in two series of containers. A single series consisted of four containers with surface water, hypolimnion water and no perturbed core sediment and supernatant water from the test basin. Various types of coagulants (PAX 18, PAX 19H, ALCAT) were added to the three containers. The dosages of substance were specified in the initial experimental studies. One container served as a control. Coagulants were added evenly into surface water.

Analysis. The $\mathrm{pH}$ was measured by the multiparameter WTW Multi Line $\mathrm{P} 4$. The $\mathrm{pH}$ meter was calibrated daily using $\mathrm{pH}$ 4.01, $\mathrm{pH} 7.01$ and 10.1 buff- ers. The dissolved oxygen and percentage of oxygen saturation were determined using YSI PROODO. The turbidity and colour were analysed by the Spectrophotometer UV/Vis (Nanocolor).

Floc formation. The dynamic floc sizes were measured visually as coagulation and flocculation processes proceeded. The rate of coagulation was measured in Imhoff cones. In a given time the volume of formed aggregates was noted. On this basis, the sedimentation curve was plotted on a graph.

\section{Results and discussion}

Figures 1 and 2 show the variation of residual turbidity and colour removal efficiencies in terms of coagulant dosages (3.67 and $7.54 \mathrm{mg} \mathrm{dm}^{-3}$ for PACl as $\mathrm{Al}$ ). Figure 1(a) shows that the coagulant type and dosage significantly affected the colour and turbidity. For PACl the residual turbidity of effluents decreased with the increasing coagulant dosages and consistently increased as the coagulant dosages further increased. The residual turbidity was higher than 5 NTU at the coagulant dosage $7.54 \mathrm{mg} \mathrm{dm}^{-3}$ as $\mathrm{Al}$.

The final $\mathrm{pH}$ values (Fig. 3) of the solutions for each experiment were also recorded. It should be noted that the effluent $\mathrm{pH}$ after all $\mathrm{PACl}$ flocculation remained neutral. Based on the experimental results mentioned above, a combined optimal dosage for turbidity and colour removal was about $3.67 \mathrm{mg} \mathrm{Al}$. $\mathrm{dm}^{-3}$ for $\mathrm{PACl}$, but greater phosphorus decrease required a higher dosage. For example, turbidity removal efficiencies by PAX 18, PAX XL $19 \mathrm{H}$ and ALCAT were $81.8 \%$, $85.7 \%$ and $88.3 \%$ at the optimal dosage, respectively; turbidity removal efficiencies of PAX 18, PAX XL 19H and ALCAT were $61.1 \%, 55.6 \%$ and $72.2 \%$ at the optimal dosage, respectively. Xu et al. (2010) also found that coagulating species with higher cationic charge perform better than those with lower cationic charge.

The final DO (dissolved oxygen) values (Fig. 4) of the solutions for each experiment were also noted. It should be recorded that the values of DO after ALCAT and PAX 18 flocculation decreased by about $20 \%$, while the DO values after PAX XL19H flocculation were lower by ca. $15 \%$. A similar finding was reported by Hanson et al. (2006), suggesting that the decrease in DO was caused by lower primary production.

Dynamic variation of floc size during flocculation. The analysis of sedimentation of flocs was measured for $220 \mathrm{~min}$ at the two dosages and the results are shown in Fig. 5. Compared to all substances, PAX 18 


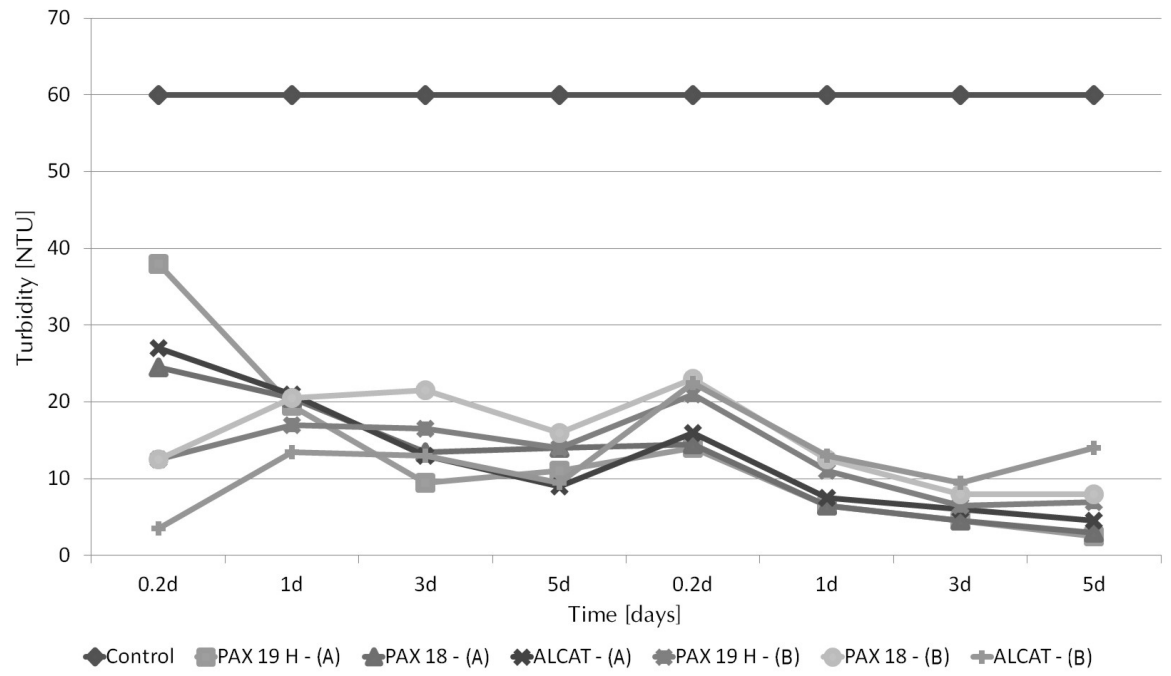

Fig. 1. The dynamic of changes in turbidity for ALCAT, PAX 18 and PAX XL19H; A - at lower dose, B - at higher dose

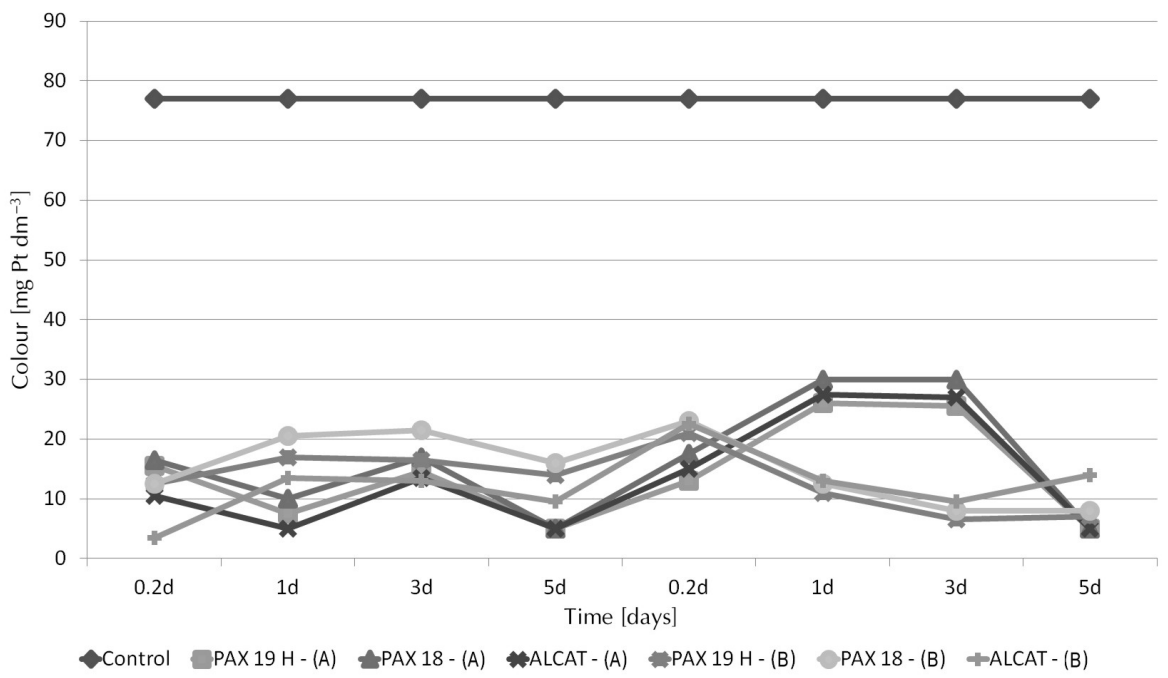

Fig. 2. The dynamic of changes in colour for ALCAT, PAX 18 and PAX XL19H; A - at lower dose, B - at higher dose

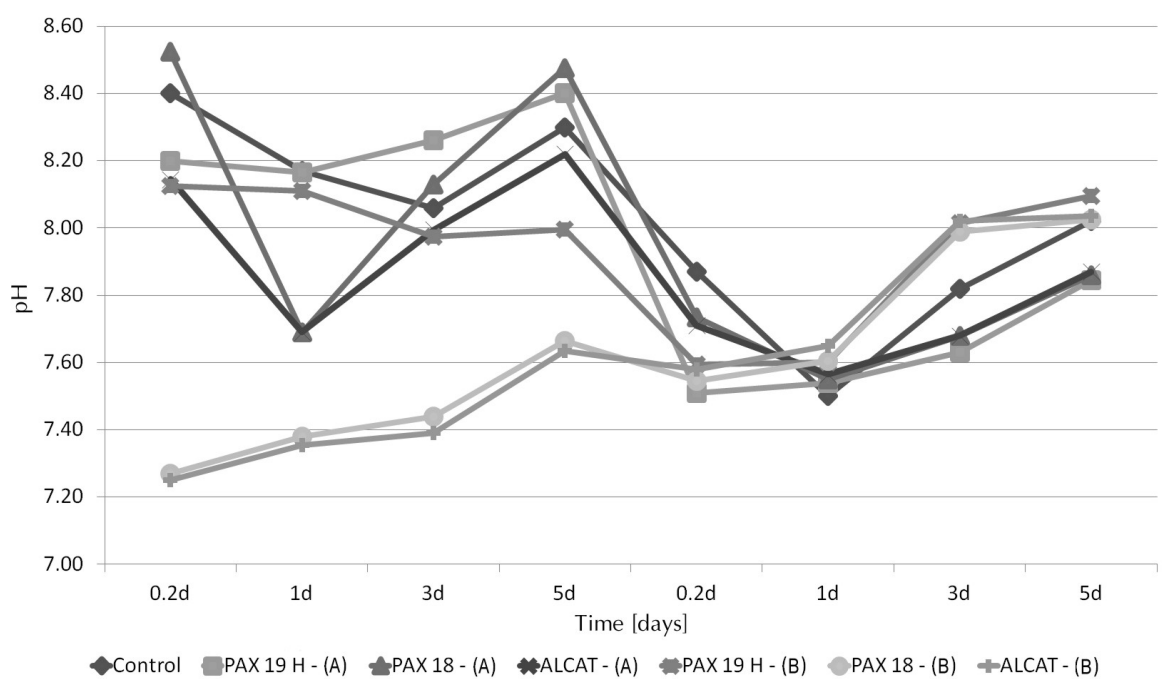

Fig. 3. The dynamic of changes in reaction for ALCAT, PAX 18 and PAX XL19H; A - at lower dose, B - at higher dose 


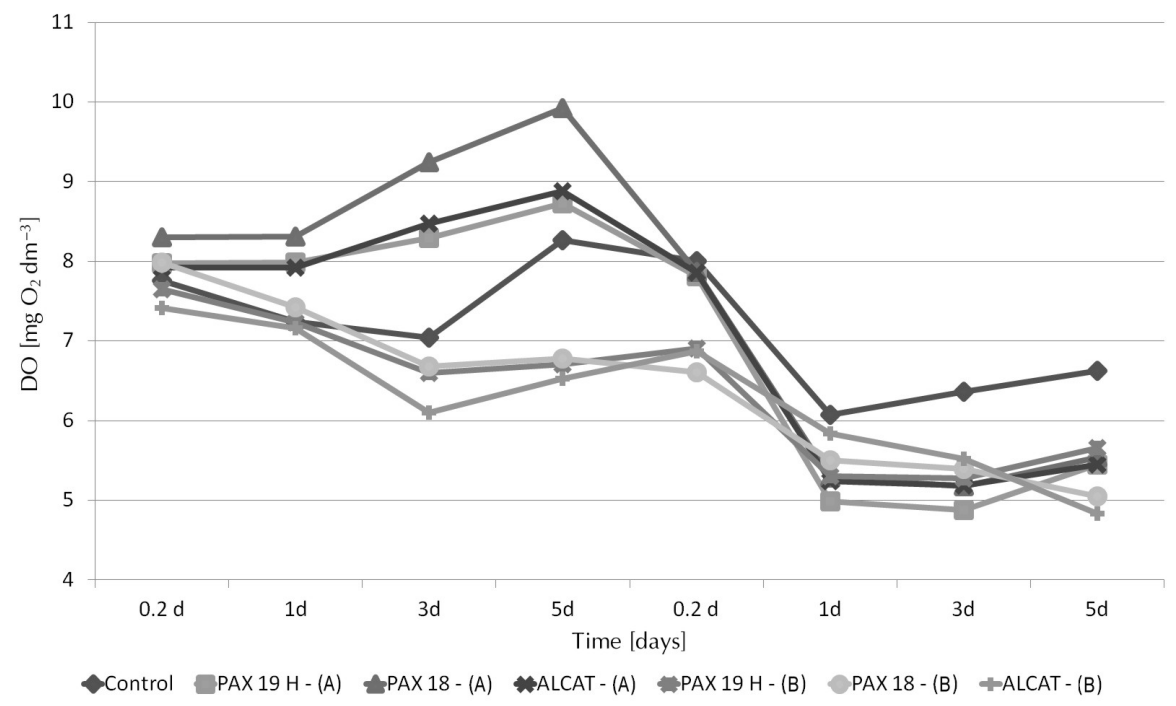

Fig. 4. The dynamic of changes in dissolved oxygen (DO) for ALCAT, PAX 18 and PAX XL19H; A - at lower dose, B - at higher dose

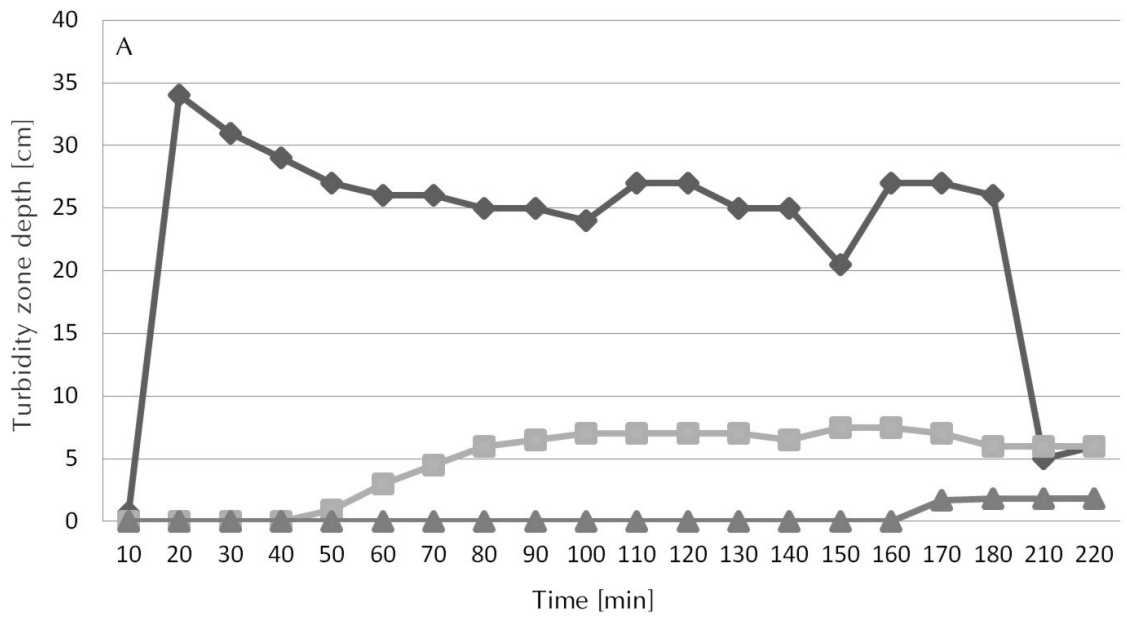

$\triangle P A X X L 19 H$ PAX 18 ALCAT

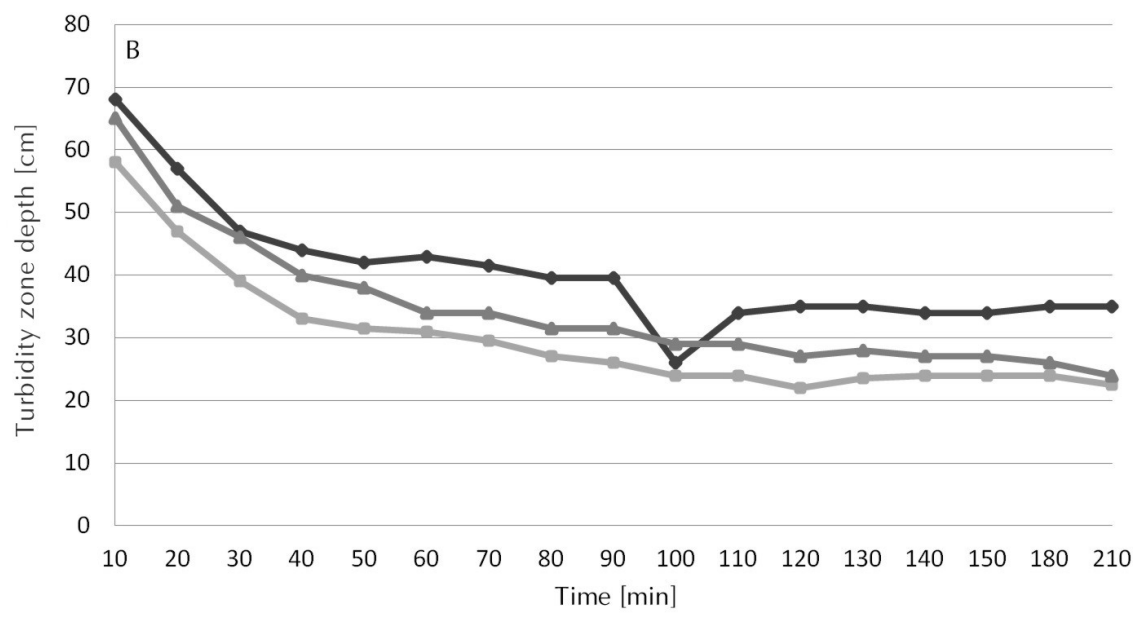

$\leadsto$ PAXXL19H $\rightleftharpoons$ PAX $18 \leadsto$ ALCAT

Fig. 5. The curve of sedimentation of coagulants; A - at lower dose, B - at higher dose 
and ALCAT exhibited faster floc growth rate and larger floc size. The floc trough during of the ALCAT and PAX 18 flocculation process showed a sharp increase in size during the first $40 \mathrm{~min}$, followed by a slight increase in floc size during the next period, and formed huge aggregates consisting of particles of organic matter and coagulant and settled down. The sharp growth in floc size in the first $40 \mathrm{~min}$ is likely due to the aggregation of particles. Boller and Blaser (1998) reported that larger particles generally settled down more quickly than smaller particles of similar density. So, both coagulants had a short retention time. In contrast, the flocs formed by the ALCAT coagulant were more stable and the breakage of flocs seldom appeared during the growth period. The dynamics of sedimentation of flocs at a lower dosage were very unstable. In a given time only small particles were formed, which were not linked in larger forms (ALCAT) or decomposed (PAX 18 and PAX XL 19H). After 220 minutes, the presence of micro-flocs was revealed in the volume of samples, which did not avoid density and did not settle at the bottom. A similar rate was observed during rapid mixing, when the flocs broke and the curve of balance was disturbed (Zhao et al. 2011).

\section{Conclusions}

The coagulation and sedimentation performance of PAX 18, PAX XL 19H and ALCAT was investigated with Łajskie Lake water in terms of the basic water quality parameters, and the coagulation and sedimentation mechanism of aggregated flocs. ALCAT and PAX 18 were very effective in removing turbidity and colour compared to PAX XL 19H. The average size of flocs formed by ALCAT was larger than those by PAX during the growth period. However, the sedimentation rate by ALCAT appeared to be better; this is caused by the addition of polyelectrolyte, which stabilizes the flocs. The flocs were formed not only by a charge neutralization mechanism but also might be held together by a chemical bonding rather than a physical bond. The dosage impacted on linking flocs. At a lower dosage, flocs were characterized as small particles, which very slowly settled down. However, a small difference in phosphorus removal from water was noted. At double the dose, the percentage of phosphorus removal was higher by about $20 \%$ and the curve of sedimentation was more stable.

\section{Acknowledgment}

The first author was funded by a DrINNO 3 scholarship by the European Union within the European Social Fund (contract 4/2013).

\section{References}

Aguilar M.I., Saez J., Llorens M., Soler A., Ortuno J.F., 2003, Microscopic observation of particle reduction in slaughterhouse wastewater by coagulation-flocculation using ferric sulphate as coagulant and different coagulant aids, Water Res. 3799): 2233-2241.

Biggs C.A., Lant P.A., 2000, Activated sludge flocculation: on-line determination of floc size and the effect of shear, Water Res. 34(9): 2542-2550.

Boller M., Blaser S., 1998, Particles under stress, Water Sci. Technol. 37(10): 9-29.

Chaignon V., Lartiges B.S., El Samrani A., Mustin C., 2002, Evolution of size distribution and transfer of mineral particles between flocs in activated sludges: an insight into floc exchange dynamics, Water Res. 36(3): 476-484.

Cleasby J.L., Logsdon G.S., 1999, Granular Bed and Precoat Filtration, [in:] American Water Works Association (Letterman R.D., tech. ed.), Water Quality and Treatment: A Handbook of Community Suppliers, McGraw -Hill, New York: 8.1-99.

Conley, D.J., Paerl, H.W., Howarth, R.W., Boesch, D.F., Seitzinger, S.P., Havens, K.E., Lancelot, C., Likens, G.E., 2009, Ecology: controlling eutrophication: nitrogen and phosphorus, Science 323 (5917): 1014-1015.

Cooke G.D., Welch E.B., Peterson S.A., Newroth P.R., 1993, Restoration and Management of Lakes and Reservoirs, Lewis Publ., Boca Raton, p. 548.

Ducoste J.J., Clark M.M., 1998, The influence of tank size and impeller geometry on turbulent flocculation: I. Experimental, Environ. Eng. Sci. 15(3): 215-224.

Francois R.J., 1987, Strength of aluminium hydroxide flocs, Water Res. 21(9): 1023-1030.

Haghseresht F., Wang S., Do D.D., 2009, A novel lanthanummodified bentonite, Phoslock, for phosphate removal from wastewaters, Appl. Clay Sci. 46: 369-375

Hanson P.C., Carpenter S.R., Armstrong D.E., Emily H. Stanley E.H., Kratz T.K., 2006, Lake dissolved inorganic carbon and dissolved oxygen: changing drivers from days to decades, Ecol. Monogr. 76(3): 343-363.

Harris, G. P., 1997, Algal biomass and biogeochemistry in catchments and aquatic ecosystems: scaling of processes, models and empirical tests, Hydrobiologia 349: 1926.

Li T., Zhu Z., Wang D., Yao C., Tang H., 2007, The strength and fractal dimension characteristics of alum-kaolin flocs, Int. J. Miner. Process. 82: 23-29. 
Özkundakci D., Hamilton D.P., Scholes P., 2010, Effect of intensive catchment and in-lake restoration procedures on phosphorus concentrations in a eutrophic lake, Ecol. Eng. 36(4): 396-405.

Parker D.S., Kaufman W.J., Jenkins D., 1972, Floc breakup in turbulent flocculation processes, J. Sanit. Eng. Div. 98: 79-99.

Rydin E., Welch E.B., 1998, Aluminum dose required to inactivate phosphate in lake sediments, Water Res. 32(10): 2969-2976.
Spicer P.T., Pratsinis S.E., 1996, Shear-induced flocculation: the evolution of floc structure and the shape of the size distribution at steady state, Water Res. 30(5): 1049-1056.

Yu W.Z., Li G.B., Xu Y.P., 2009, Breakage and re-growth of flocs formed by alum and PACl, Powder Technol. 189: 439-443.

Zhao Y.X., Gao B.Y., Cao B.C., Yanga Z.L., Yue Q.Y., Shon H.K., Kim J-H., 2011, Comparison of coagulation behavior and floc characteristics of titanium tetrachloride (TiCl4) and polyaluminum chloride (PACl) with surface water treatment, Chem. Eng. J. 166(2): 544-550. 